\title{
FABRICATION OF IMPROVED SIGE ALLOYS FOR AN 18-COUPLE MODULE TEST
}

\author{
S. Loughin, J. F. Nakahara, \\ and D. X. Centurioni \\ Martin Marietta Astro Space \\ P.O. Box 8555, Philadelphia, PA 19101-8555
}

(610) $354-3263$

\author{
B. A. Cook and J. L. Harringa \\ Ames Laboratory \\ Iowa State University \\ Ames, IA $50011-3020$ \\ (515) $294-9673$
}

\begin{abstract}
$\mathrm{N}$ - and p-type $\mathrm{Si}_{0.78} \mathrm{Ge}_{0.22}$ alloys were fabricated to determine if recently reported improvements in the figure-ofmerit, $\mathrm{Z}$, could be realized in devices. These will be tested in an 18-couple module to directly compare the performance of these materials with that of standard coarse-grain SiGe used in flight programs. We describe the synthesis by vacuum casting and hot pressing p-type SiGe and mechanical alloying and hot-isostatic pressing n-type SiGe. Improved materials and standard materials are characterized and compared. The integrated average figures-ofmerit $\left(573-1273 \mathrm{~K}\right.$ ) of the improved materials were $\overline{Z_{p}^{\text {inpr }}}=0.59 \times 10^{-3} \mathrm{~K}^{-1}$ and $\overline{Z_{n}^{\text {inpr }}}=0.85 \times 10^{-3} \mathrm{~K}^{-1}$ compared with $\overline{Z_{p}^{s t d}}=0.52 \times 10^{-3} \mathrm{~K}^{-1}$ and $\overline{Z_{n}^{s t d}}=0.76 \times 10^{-3} \mathrm{~K}^{-1}$ for the standard materials. We also report the power factors for improved and standard materials removed from fabricated devices to gain insight as to how subsequent processing impacts performance.
\end{abstract}

\section{INTRODUCTION}

The composition of the $\mathrm{Si}_{0.78} \mathrm{Ge}_{0.22}$ thermoelectric alloys which are currently operating in the Radioisotope Thermoelectric Generators (RTGs) on board the Voyager, Galileo, and Ulysses spacecraft, are doped with less boron, for p-type, and phosphorus, for n-type, than is currently considered optimal. Recent improvements in the thermoelectric figure-of-merit of SiGe alloys have been reported by several investigators (Fleurial 1993 and Cook 1994a) through compositional and processing refinements. Figures-of-merit of $0.9 \times 10^{-3} \mathrm{~K}^{-1}$ and $0.6 \times 10^{-3} \mathrm{~K}^{-1}$ have been reported for $\mathrm{n}$ - and p-type $\mathrm{SiGe}$, respectively, based on measurements of small, laboratory-scale specimens. For the p-type alloy, the improvements have been easily obtained by increasing the amount of boron added as a dopant, and by improving the homogeneity of the material. For the n-type alloy, however, the solubility of phosphorus is limited to a value less than optimum. However, it has been shown that the addition of gallium can enhance the solubility of phosphorus in these materials through a III-V ion pairing interaction. In addition to these compositional changes, the use of mechanical alloying has been shown (Cook 1993) to be a viable method of preparing large, production-scale compacts. In order to more accurately predict the performance that can be realized with these materials in an actual converter, the materials will be used to fabricate unicouples, eighteen of which will then be assembled into a small-scale test module to compare with previous results (Kelly 1994 and Nakahara 1995).

\section{MATERIAL PREPARATION}

Improved P-Type Alloy

As shown in Figure 1, the p-type improved material was produced by a process of melting, chill-casting, pulverizing, and hot pressing (Loughin 1993). Three initial castings were prepared. For each casting, the crucible was loaded with $266.9 \mathrm{~g} \mathrm{Si}, 172.4 \mathrm{~g} \mathrm{Ge}$, and $0.6453 \mathrm{~g} \mathrm{~B}$. The furnace was evacuated and the charge was inductively heated to $1723 \pm 20 \mathrm{~K}$. After $1-2$ minutes, the temperature was allowed to decrease slightly to $1693 \pm 5 \mathrm{~K}$, and the melt was poured into a water-chilled copper mold previously coated with amorphous graphite (AquaDAG) as a mold release. The resulting ingots were rectangular prisms, $12.5 \times 91.3 \times 127.0 \mathrm{~mm}$. These were crushed and ball milled to produce three lots of powder, with median grain sizes of $5.0,6.3$, and $5.8 \mu \mathrm{m}$, respectively.

Each lot was vacuum-hot-pressed following the schedule shown in Table 1. This resulted in three compacts which were subsequently recrushed and remilled to obtain three lots of powder with median grain sizes of 5.5, 5.2, and 5.4 $\mu \mathrm{m}$, respectively. The powders were blended to produce a master lot of $1.19 \mathrm{~kg}$ of powder with a median grain size of $5.4 \mu \mathrm{m}$. Mold charges of 397 grams were drawn from this master lot, and pressed into three compacts following the schedule shown in Table 1. Each compact weighed about 394 grams and about $2.8 \mathrm{~cm}$ thick by $7.6 \mathrm{~cm}$ in diameter. The first of these compacts, designated CAS4882B-1, was machined to obtain the samples for material characterization as presented here. 


\section{DISCLAIMER}

This report was prepared as an account of work sponsored by an agency of the United States Government. Neither the United States Government nor any agency Thereof, nor any of their employees, makes any warranty, express or implied, or assumes any legal liability or responsibility for the accuracy, completeness, or usefulness of any information, apparatus, product, or process disclosed, or represents that its use would not infringe privately owned rights. Reference herein to any specific commercial product, process, or service by trade name, trademark, manufacturer, or otherwise does not necessarily constitute or imply its endorsement, recommendation, or favoring by the United States Government or any agency thereof. The views and opinions of authors expressed herein do not necessarily state or reflect those of the United States Government or any agency thereof. 


\section{DISCLAIMER}

Portions of this document may be illegible in electronic image products. Images are produced from the best available original document. 
resistuvity, thermal conductuvity as a function of temperature. The integrated average (573-1273 K) figures-of-merit for the improved materal are $0.58 \times 10^{-3} \mathrm{~K}^{-1}$ and $0.86 \times 10^{-3} \mathrm{~K}^{-1}$ for the p-type and n-type alloys, respectuvely. We must compare these values with $0.52 \times 10^{-3} \mathrm{~K}^{-1}$ and $0.76 \times 10^{-3} \mathrm{~K}^{-1}$ for p-type and n-type standard Cassini alloys, respecuvely. This represents an improvement of $11 \%$ for the p-type alloy and $13 \%$ for the n-type alloy. Figure 8 presents a companison of the improved figures-of-merit with those of standard Cassinı materials.

TABLE 2. Room Temperature Hall Effect Measurements for the Cassinı Materıals.

\begin{tabular}{|l||c|c|c|c|}
\hline Sample & Treatment & $n\left(\times 10^{26} \mathrm{~m}^{-3}\right)$ & $\rho\left(\times 10^{-5} \Omega \cdot \mathrm{m}\right)$ & $\mu\left(\mathrm{cm}^{2} \cdot \mathrm{V}^{-1} \cdot \mathrm{s}^{-1}\right)$ \\
\hline \hline n-type & as pressed & 1.36 & 0.78 & 59.4 \\
n-type & 20 mın/1323 K & 1.64 & 066 & 57.4 \\
p-type, disk 2 & as pressed & 164 & 0.98 & 38.8 \\
p-type, disk 1 & $20 \mathrm{~min} / 1323 \mathrm{~K}$ & 1.59 & 0.98 & 40.2 \\
p-type, disk 2 & $4 \mathrm{hrs} / 1273 \mathrm{~K}$ & 173 & 0.98 & 369 \\
\hline
\end{tabular}
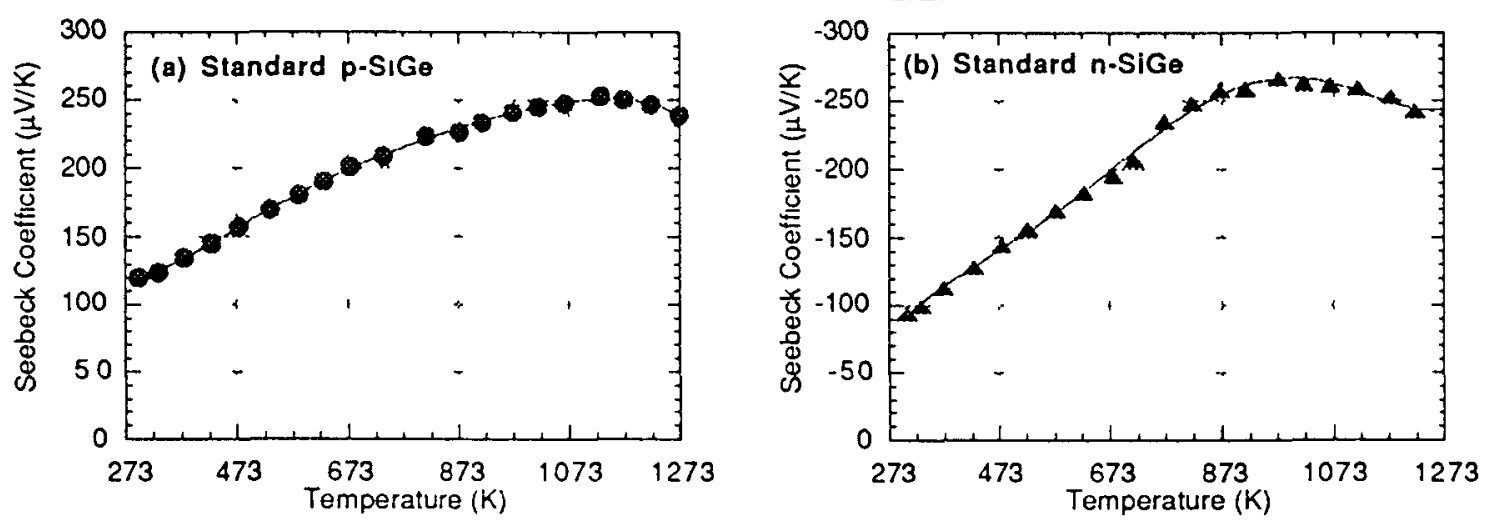

FIGURE 5. Seebeck Cœefficıent of Standard Cassinı P-Type $\mathrm{S}_{1} G e(a)$ and N-Type $\mathrm{S}_{1} \mathrm{Ge}$ (b).
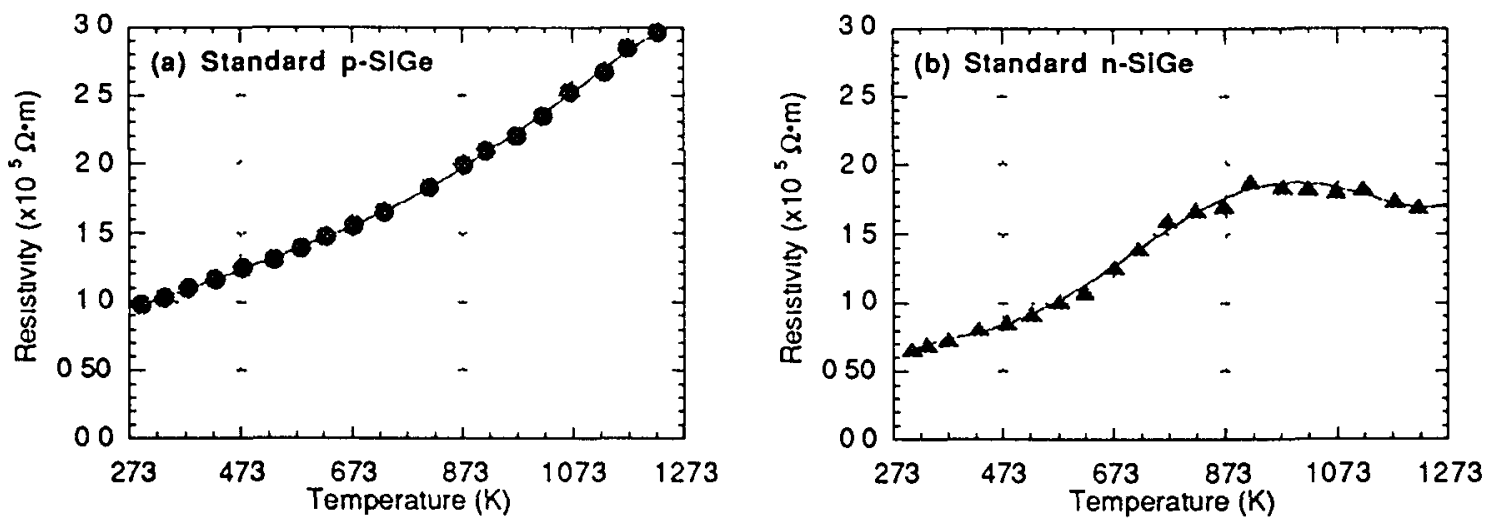

FIGURE 6. Electrical Resistuvity of Standard Cassinı P-Type $S_{1} G e$ (a) and N-Type SiGe (b).

\section{Improved and Standard Materials Post-Fabncation}

Obviously, a measured improvement in the as-fabricated state does not guarantee that the improvement will be retained in the finished devices. The devices are subjected to several high temperature cycles during assembly and these may affect the thermoelectric properties. To assess how much of the improvement is retained in the final device, we fabricated actual devices then removed the thermoelectric material for characterization. The measurements were made without further heat treatment, that is no "reset" was applied. Only the power factor, $s^{2} / p$, was measured since the geometry of the thermoelectric elements in the actual device precludes the measurement of thermal conductivity. The integrated averages of the Seebeck coefficient, electrical resistivity, and power factor, over the temperature range 573-1273 K, are compared in Table 3. 

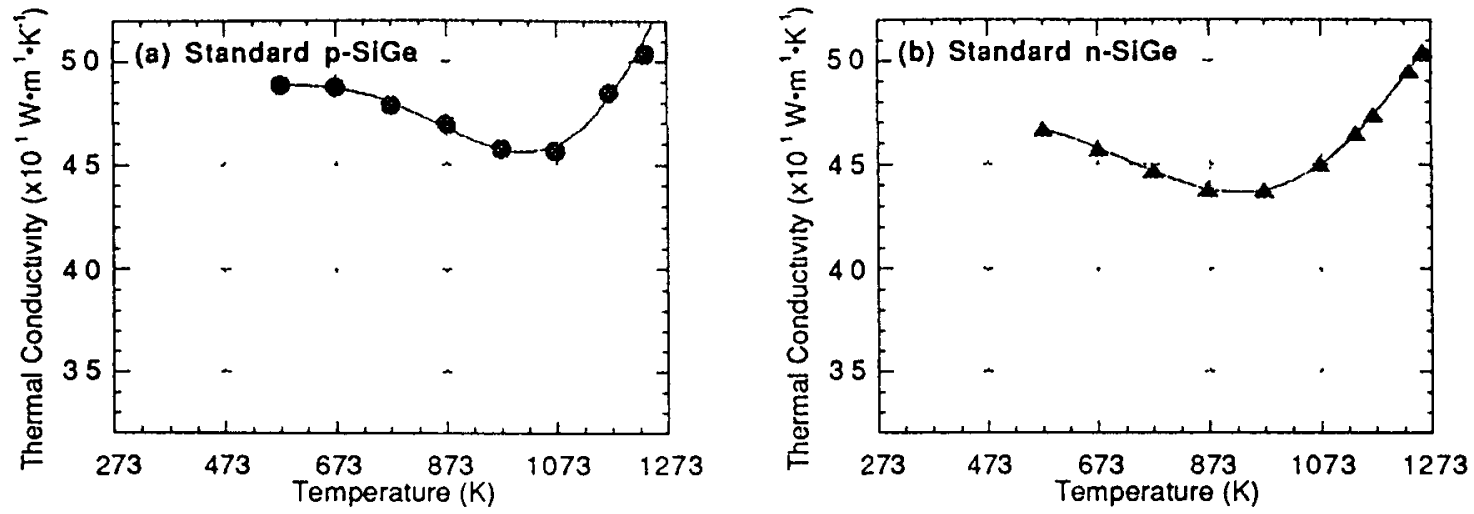

FIGURE 7. Thermal Conductuvity of Standard Cassinı P-Type SiGe (a) and N-Type SiGe (b).
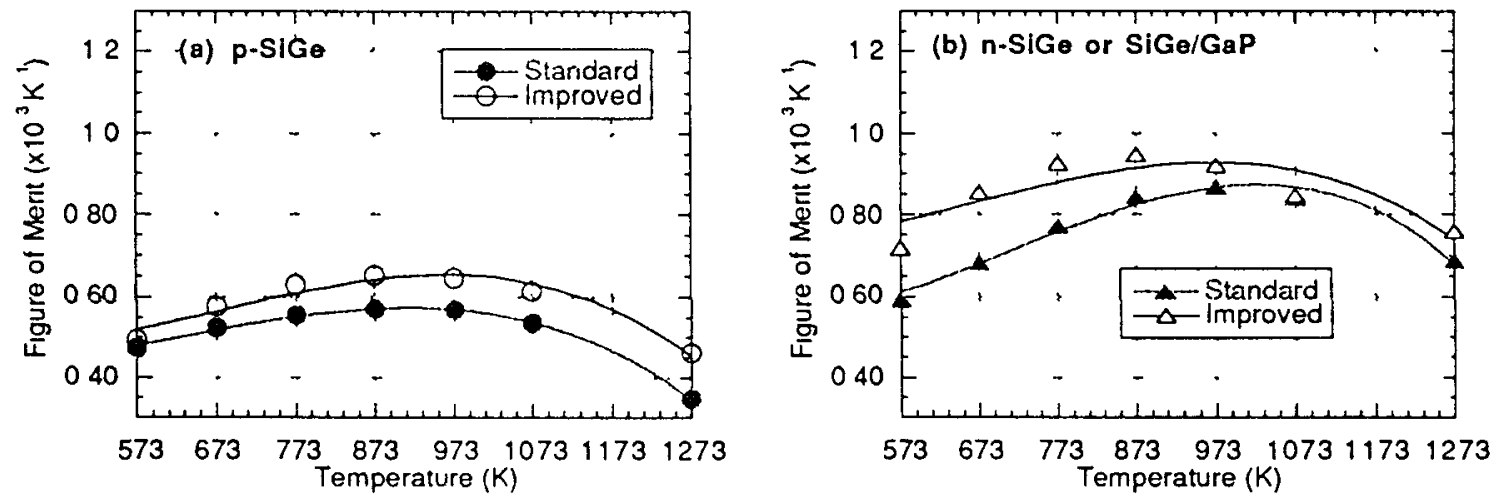

FIGURE 8. Figures-of-Merit of the Improved Materials and Standard Cassinı Matenals Compared for P-Type $S_{1} G e(a)$ and $N$-Type $S_{1} G e$ and $S_{1} G e / G a P(b)$.

TABLE 3. Comparison of Integrated Average (573-1273 K) Power Factors for Improved SiGe and Standard Cassini SiGe Alloys Removed from Unicouples after Fabrication.

\begin{tabular}{|l||c|c|c|}
\hline Material & $\begin{array}{c}\text { Seebeck } \\
(\mu \mathrm{V} / \mathrm{K})\end{array}$ & $\begin{array}{c}\text { Resistıvity } \\
\left.\left(\times 10^{-5} \Omega \cdot \mathrm{m}\right)\right)\end{array}$ & $\begin{array}{c}\text { Power Factor } \\
\left(\mu \mathrm{W} / \mathrm{cm} \cdot \mathrm{K}^{2}\right)\end{array}$ \\
\hline \hline $\mathrm{p}$-SIGe Std. Cassını & 220.6 & 2.34 & 20.8 \\
\hline $\mathrm{p}$-SIGe "Improved" & 174.6 & 1.53 & 19.9 \\
\hline $\mathrm{n}$-SIGe Std. Cassıni & -249.3 & 2.05 & 30.3 \\
\hline$n$-SIGe "Improved" & -215.9 & 151 & 30.9 \\
\hline
\end{tabular}

Because of the configuration of unicouple thermoelectric elements, we were unable to characterize the thermal conductivity changes occurring during fabrication. However, if we assume that the only change in thermal conductivity is in the electronic component, $\Lambda_{\mathrm{e}}=\mathscr{D}_{0} \sigma \mathrm{T}$, then, using calculated values (Vining 1991a and 1991b) for the Lorentz factor, $\mathscr{L}_{0}$, we can estımate the post fabrication thermal conductivities. Using these values, we expect that the improved $n$-type material will retain a significant advantage over the standard $n$-type material after device fabrication. This may be due, in part, to the fact that the presence of $\mathrm{GaP}$ will suppress the precipitation of phosphorus. However, the improved p-leg material may offer only a modest advantage, because the dopant precipitation effects in both the improved and standard materials will be fairly similar.

\section{CONCLUSIONS}

In conclusion, we have demonstrated that improved $\mathrm{Si}_{0.78} \mathrm{Ge}_{0.22}$ thermoelectric alloys can be fabricated in production-scale quantities sufficient to support production of an 18-couple test module. The improved p-type material was found to have an integrated average (573-1273 K) figure-of-ment of $0.59 \times 10^{-3} \mathrm{~K}^{-1}$, compared with a value of $0.52 \times 10^{-3} \mathrm{~K}^{-1}$ for the baselıne material. Over the same temperature range, the integrated average figure-of- 
merit of the improved n-type material ranged from $0.84 \times 10^{-3}$ to $0.86 \times 10^{-3} \mathrm{~K}^{-1}$, compared with a value of $0.76 \times 10^{-3} \mathrm{~K}^{-1}$ for the baseline material. Judging by the measured power factor of baseline and improved materials taken from completed devices, these improvements are largely retained through the fabrication process. This conjecture will be tested in future work, once the 18-couple module fabrication and test are completed. Also, the hot isostatic pressing method employed to produce the n-type material is a new and distinctly different consolidation process. Some small-scale samples prepared by this technique had figures-of-merit as high as $0.92 \times 10^{-3} \mathrm{~K}^{-1}$, thus encouraging us to expect further improvements in the n-type figure-of-merit for production-scale compacts as this new technique is further optimized and refined.

\section{Acknowledgments}

The authors gratefully acknowledge the support of the U.S. Department of Energy under contracts W-7405-ENG82 and DE-AC03-91SF18852. In addition we would like to thank Dr. William Barnett, of the U.S. DoE, Dr. Cronin Vining, and Mr. Robert F. Hartman, of Martin Marietta, for their insightful comments and discussion.

\section{References}

Cook, B.A., J.A. Harringa, S. Loughin, and D.X. Centurioni (1994) "Large-Scale Production of $\mathrm{Si}_{0.8} \mathrm{Ge}_{0.2}$ Thermoelectric Alloys by Mechanical Alloying," Proc. 28th Intersoc. Energy Conversion Eng. Conf., 8-13 Aug 1993, Atlanta GA. Washington DC: Am. Chem. Soc. 1: 234 - 237.

Cook, B.A., J.L. Harringa, S.H. Han, C. Alexander, B.J. Beaudry, and K.A. Gschneidner, Jr. (1994) Advanced Thermoelectrics Program: Silicon Germanium and Advanced Materials. Ames IA: Ames Laboratory, Quarterly Progress Report for US DoE Contract No. W-7405-ENG-82, dated 1-Jan through 31-Mar-94.

Cook, B.A., J.L. Harringa, and B.J. Beaudry (1993) "A Solid State Approach to the Production of Kilogram Quantities of Si80Ge20 Thermoelectric Alloys." Proc. 10th Symposium on Space Nuclear Power and Propulsion, Albuquerque, NM, 10-14 Jan 1993. New York, NY: AIP Conf. Proc. no. 271, 2: 777-783.

Fleurial, J-P., J. Vandersande, N. Scoville, C. Bajgar, and J. Beaty (1993) "Progress in the Optimization of n-Type and p-Type SiGe Thermoelectric Materials." Proc. 10th Symposium on Space Nuclear Power and Propulsion, Albuquerque, NM, 10-14 Jan 1993. New York, NY: AIP Conf. Proc. no. 271, 2: 759-764.

Kelly, C.E. and P.M. Klee (1994) "Cassini RTGs - Small Scale Module Tests," Proc. 29th Intersoc. Energy Conversion Eng. Conf., 7-11 Aug 1994, Monterey CA. Washington DC: AIAA 1: 554-558 .

Loughin, S., D.X. Centurioni, A.G. Robison, J.J. Maley and J-P. Fleurial (1993) "High-Boron P-Type Silicon Germanium Thermoelectric Material Prepared by the Vacuum Casting and Hot Pressing Method," Proc. 10th Symposium on Space Nuclear Power and Propulsion, Albuquerque, NM, 10-14 Jan 1993. New York, NY: AIP Conf. Proc. no. 271, 2: 747-752.

Maurice, D.R. and T.H. Courtney (Feb 1990) "The Physics of Mechanical Alloying: A First Report." Metallurgical Transactions A, 21A: 289.

Nakahara, J.F., B. Franklin, and L.E. DeFillipo (1995) "Development of an Improved Performance SiGe Unicouple," Proc. 12th Symposium on Space Nuclear Power and Propulsion, Albuquerque NM 8-12 Jan 1995. (to be published).

U.S. Dept of Energy (1991) GPHS-RTGs in Support of the Cassini Mission. San Francisco CA: U.S. Dept. of Energy Contract DE-AC03-91SF18852.

Vining, C.B. (1991) "A Model for the High-Temperature Transport Properties of Heavily Doped n-Type SiliconGermanium Alloys," J. Appl. Phys., 69(1): 331-341.

Vining, C.B. (1991) "A Model for the High Temperature Transport Properties of Heavily Doped p-Type SiliconGermanium Alloys," in Modern Perspectives on Thermoelectrics and Related Materials, D.D. Allred, C.B. Vining and G.A. Slack, eds. Pittsburgh, PA: Proc. Mat. Res. Soc., 234: 95-104. 
TABLE 1. Temperature / Pressure Profile for Vacuum Hot Pressing of Improved P-Type SiGe Compacts.

\begin{tabular}{|c||c|c|c|c|}
\hline $\begin{array}{c}\text { Elapsed } \\
\text { Time } \\
\text { (minutes) }\end{array}$ & $\begin{array}{c}\text { Heat / Cool } \\
\text { Rate } \\
(\mathrm{K} / \mathrm{min})\end{array}$ & $\begin{array}{c}\text { Soak } \\
\text { Temperature } \\
(\mathrm{K})\end{array}$ & $\begin{array}{c}\text { Applied } \\
\text { Pressure } \\
(\mathrm{MPa})\end{array}$ & Operation \\
\hline \hline 0 & 34 & - & 140 & Heat Up \\
\hline 40 & - & 1633 & 140 & Soak \\
\hline 130 & - & 1633 & 0 & Begin to Extrude \\
\hline 136 & 23 & - & 0 & Vacuum Cool \\
\hline 156 & 15 & - & 0 & Rapid Gas Cool \\
\hline
\end{tabular}

(a) Improved p-type $\mathrm{Si}_{0.796} \mathrm{Ge}_{0.199 \mathrm{~B}_{0.005}}$

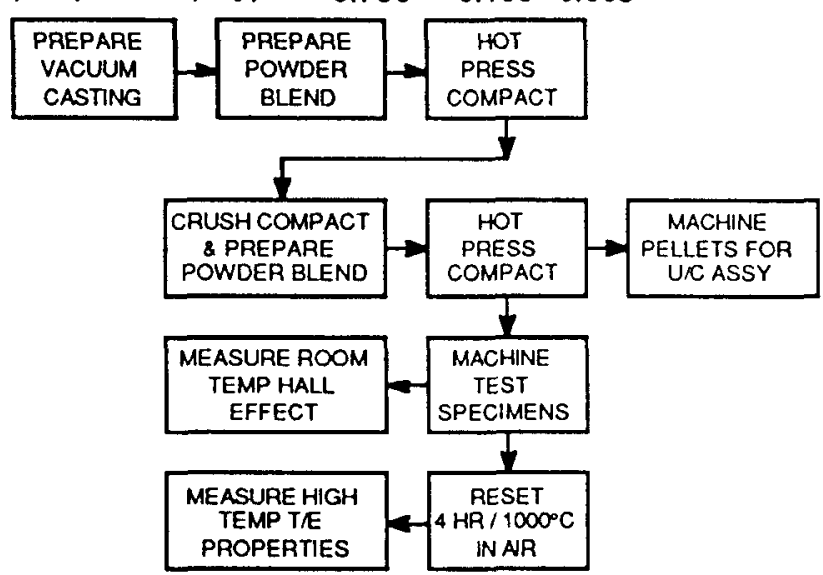

(b) Improved n-type $\mathrm{Si}_{0.784} \mathrm{Ge}_{0.197} \mathrm{Ga}_{0.005} \mathrm{P}_{0.015}$

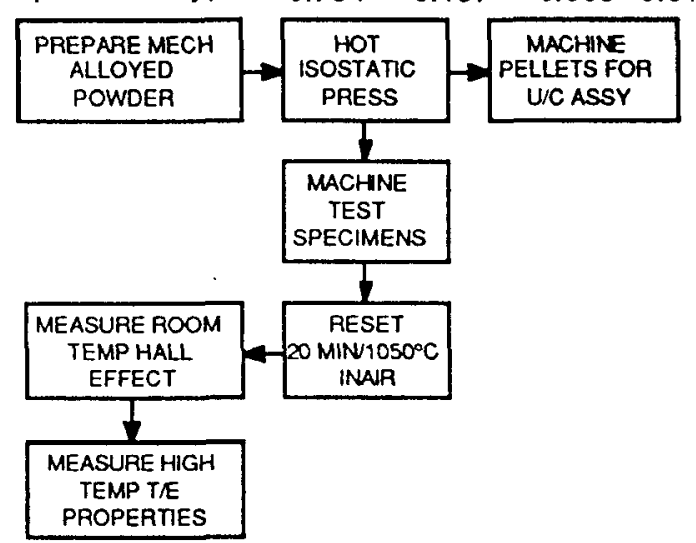

FIGURE 1. Fabrication Process for Improved P-Type SiGe (a) and N-Type SiGe/GaP (b) Alloys.

Improved N-Type Alloy

As shown in Figure 1, the n-type SiGe/GaP material was prepared by mechanically alloying (Maurice 1990) the elements to a fine powder, then consolidating the powder by hot isostatic pressing. A nominal composition of $\mathrm{Si}_{0.784} \mathrm{Ge}_{0.197} \mathrm{Ga}_{0.005} \mathrm{P}_{0.015}$ was selected based on previous results obtained on small-scale samples. The elements were weighed out in a He-filled glove box to form 20 gram charges, loaded into steel vials along with a number of hardened steel balls, and first mechanically milled for 2 hours to produce a uniform particle size, then mechanically alloyed for 6 hours in a He atmosphere. Alloy formation was verified by $\mathrm{x}$-ray diffraction.

The alloy powder was stored in an inert atmosphere until 60 to 75 grams of powder were accumulated. In order to consolidate the powder, it was loaded into a $50.8 \mathrm{~mm}$ diameter, by either 25.4 or $38.1 \mathrm{~mm}$ high canister fabricated from $0.508 \mathrm{~mm}$ thick Ta foil, the interior surface of which was lined with graphite-foil. A tantalum cover was placed on the canister, and the assembly was transferred in a sealed, helium-filled bag, to an e-beam welder where the cover was welded to the canister under a vacuum of $10^{-5}$ torr. The sealed canister was loaded into the hot isostatic press, and heated to $1403 \mathrm{~K}$, then the pressure was increased over 45 minute period to $138 \mathrm{MPa}(20 \mathrm{ksi})$, after which both pressure and temperature were maintained for 45 minutes. The final dimensions of the compact, upon removal from the tantalum canister, were approximately $42 \mathrm{~mm}$ diameter by $13-19 \mathrm{~mm}$ thick (center versus edge). Samples were machined for room temperature Hall effect measurement and high temperature thermoelectric property evaluation.

\section{BESULTS AND DISCUSSION}

\section{Improved Materials}

The improved alloys were evaluated to determine their thermoelectric properties. For the improved $n$ - and p-type alloys, Figures 2, 3, and 4 show the Seebeck coefficient, S; the electrical resistivity, $\rho$; and the thermal conductivity, $\Lambda$; respectively. For the p-type material, the properties were measured on samples from compact CAS4882B-1, with a $1273 \mathrm{~K} / 4$ hour heat treatment, or "reset", applied. For the n-type material, each of these properties was measured on samples from two compacts, HIP-15 and HIP-17, with a $1323 \mathrm{~K} / 20$ minute reset applied. 

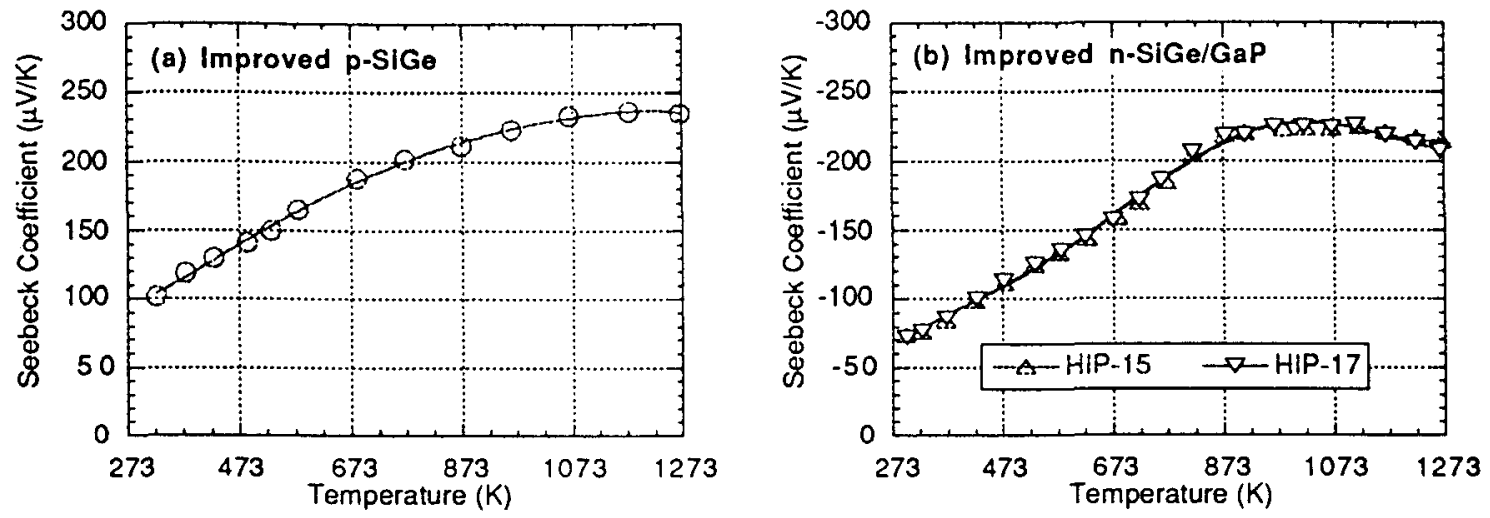

FIGURE 2. Seebeck Coefficient of Improved P-Type SiGe (a) and N-Type SiGe/GaP (b).
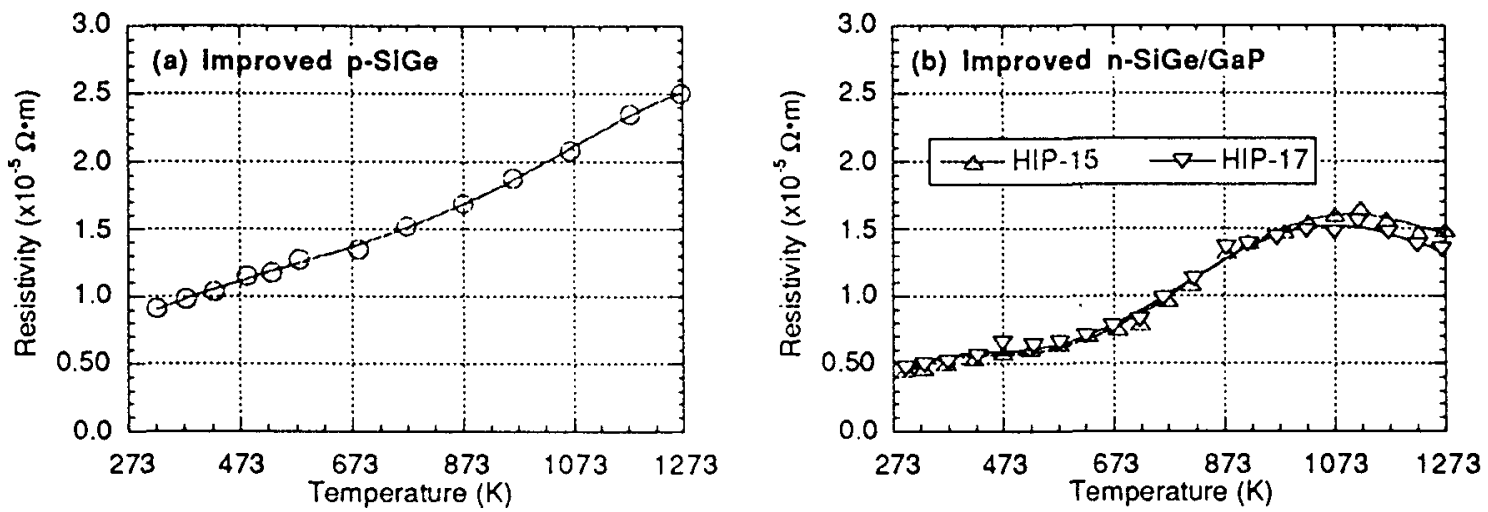

FIGURE 3. Electrical Resistivity of Improved P-Type SiGe (a) and N-Type SiGe/GaP (b).
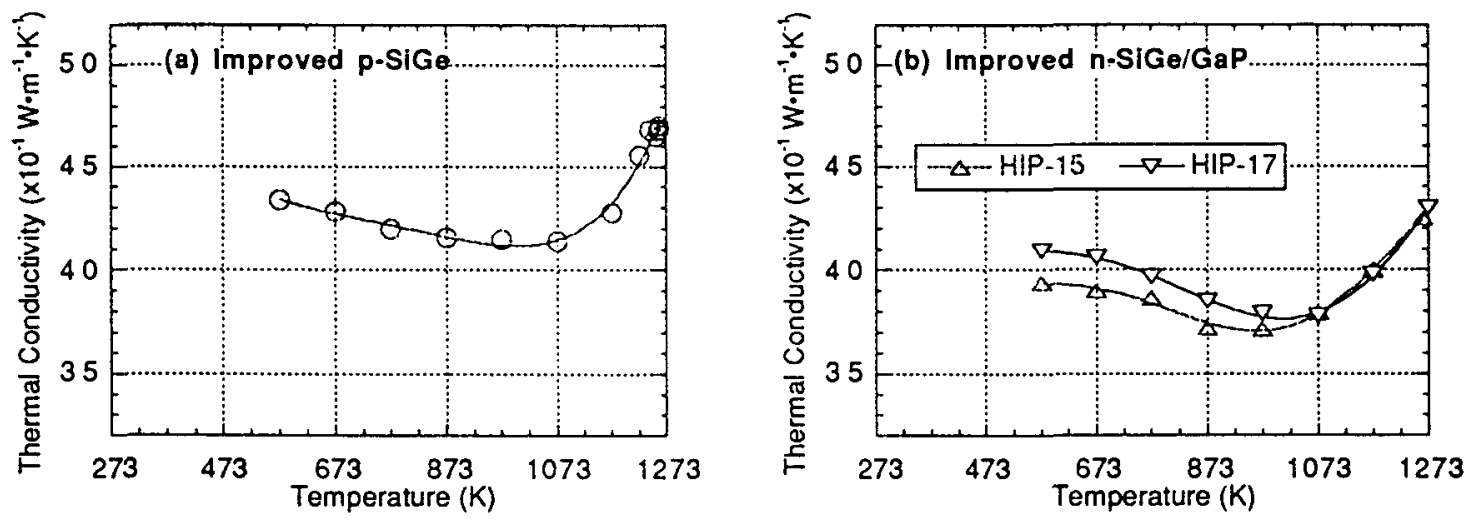

FIGURE 4. Thermal Conductivity of Improved P-Type SiGe (a) and N-Type SiGe/GaP (b).

\section{Standard Cassini Alloys}

Ultimately, the performance of any improved material must be evaluated with respect to the material it is intended to replace, preferably employing the same measurement techniques and apparatus for both. For this purpose, samples of the coarse-grain, $\mathrm{Si}_{0.78} \mathrm{Ge}_{0.22}$, thermoelectric material prepared under the Cassini RTG Contract (U.S. DOE 1991) were obtained. Four samples each, of the n-type material and p-type material were provided -- two 12.7 $\mathrm{mm}$ diameter disks and two rectangular prisms of each material. Room temperature Hall effect results are shown in Table 2 for these materials with various heat treatments (Cook 1994b). Because of dopant precipitation, these alloys are sensitive to prior thermal cycling. The applied heat treatments provide a means of redissolving precipitate phases, providing a more uniform thermodynamic condition from which to begin the measurements.

The Seebeck coefficient, electrical resistivity and thermal conductivity were measured over the temperature range 573-1273 K. For the n- and p-type Cassini materials, Figures 5, 6 and 7, present the Seebeck coefficients, electrical 